Review

\title{
The role of ophthalmic imaging in central nervous system degeneration in systemic lupus erythematosus
}

\author{
Arnaldo Dias-Santos a,b,c, , Rita Pinto Proença a ${ }^{\mathrm{a}}$, Joana Tavares Ferreira a,b,c, Sofia Pinheiro ${ }^{\mathrm{d}}$, João Paulo Cunha ${ }^{\mathrm{a}, \mathrm{c}}$, \\ Rui Proença ${ }^{\mathrm{e}, \mathrm{f}}$, Maria Francisca Moraes-Fontes ${ }^{\mathrm{c}, \mathrm{g}, \mathrm{h}}$ \\ a Department of Ophthalmology, Centro Hospitalar de Lisboa Central, Lisbon, Portugal \\ b Department of Ophthalmology, Hospital CUF Descobertas, Lisbon, Portugal \\ c NOVA Medical School, Universidade NOVA de Lisboa, Lisbon, Portugal \\ d Autoimmune Disease Unit, Unidade de Doenças Auto-imunes/Serviço Medicina 3, Hospital de Santo António dos Capuchos, Centro Hospitalar de Lisboa Central, Lisbon, Portugal \\ e Department of Ophthalmology, Centro Hospitalar e Universitário de Coimbra, Coimbra, Portugal \\ ${ }^{\mathrm{f}}$ Faculty of Medicine, University of Coimbra, Coimbra, Portugal \\ g Autoimmune Disease Unit, Unidade de Doenças Auto-imunes/Serviço de Medicina 7.2, Hospital Curry Cabral, Centro Hospitalar de Lisboa Central, Lisbon, Portugal \\ h Instituto Gulbenkian de Ciência, Oeiras, Portugal
}

\section{A R T I C L E I N F O}

\section{Article history:}

Received 9 January 2018

Accepted 14 January 2018

Available online 7 April 2018

\section{Keywords:}

SLE

Neuropsychiatric lupus

Neurodegeneration

Visual pathway

Optical coherence tomography

\begin{abstract}
A B S T R A C T
Systemic lupus erythematosus (SLE) is an autoimmune connective tissue disorder that can involve any organ system. Central nervous system involvement can be a severe life threatening complication, ultimately resulting in severe neurodegenerative changes. Magnetic resonance imaging suggests that neurodegeneration, which may have deleterious effects on brain function, may occur early in SLE and experimental models suggest that neuroprotection may be feasible and beneficial.

The retina is an extension of the brain. Recent ophthalmic imaging technologies are capable of identifying early changes in retinal and choroidal morphology and circulation that may reflect CNS degeneration. However, their utility in monitoring CNS involvement in SLE has been poorly studied as these have only been performed in small cohorts, in a cross-sectional design, non-quantitatively and without correlation to disease activity.

The authors aim to review the current understanding of neurodegeneration associated with SLE, with particular focus on the visual pathway. We describe the neuropathology of the visual system in SLE and the evidence for retinal and choroidal neurodegenerative and microvascular changes using optical coherence tomography technology. We aim to describe the potential role of optical imaging modalities in NPSLE diagnosis and their likely impact on the study of neuronal function.
\end{abstract}

(c) 2018 Elsevier B.V. All rights reserved.

\section{Contents}

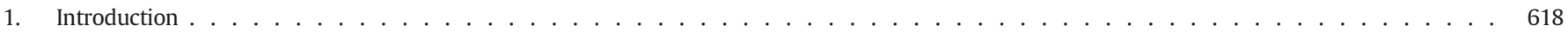

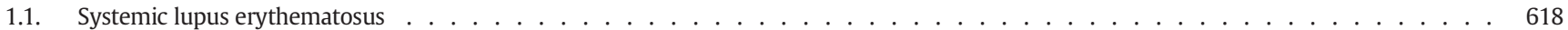

1.2. Neuropsychiatric SLE (NPSLE) - clinical features . . . . . . . . . . . . . . . . . . . . . . . . . . . . . . . . . . . . . . . . . $66_{18}$

1.3. Neuropsychiatric SLE (NPSLE) - pathophysiology . . . . . . . . . . . . . . . . . . . . . . . . . . . 618

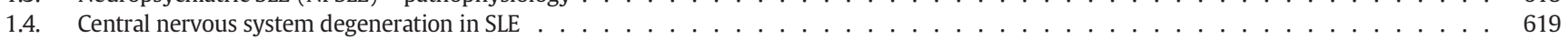

2. The eye in SLE . . . . . . . . . . . . . . . . . . . . . . . . . . . . . . . . . . . . . . . . . . . . 619

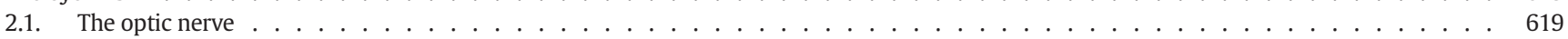

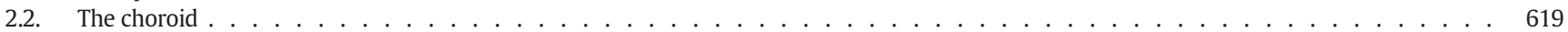

2.3. The retina . . . . . . . . . . . . . . . . . . . . . . . . . . . . . . . . . . . . . . . . . . . . 619

2.4. The retrochiasmal visual pathway . . . . . . . . . . . . . . . . . . . . . . . . . . . 620

3. Imaging the retina, optic nerve and choroid in SLE . . . . . . . . . . . . . . . . . . . . . . . . . . . . 620

3.1. Fundus fluorescein angiography and indocyanine angiography . . . . . . . . . . . . . . . . . . . . 620

3.2. Spectral domain optical coherence tomography . . . . . . . . . . . . . . . . . . . . . . . . . . . . . 620

\footnotetext{
* Corresponding author at: Hospital de Santo António dos Capuchos, Alameda de Santo António dos Capuchos, 1169-050 Lisboa, Portugal.

E-mail address: arnaldomiguelsantos@gmail.com. (A. Dias-Santos).
} 


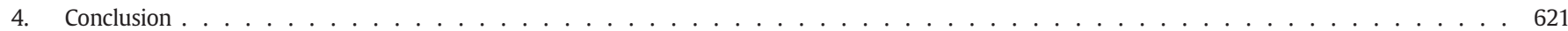

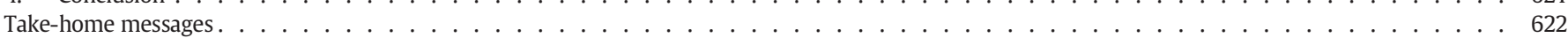

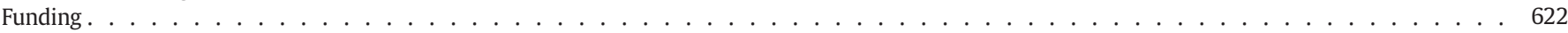

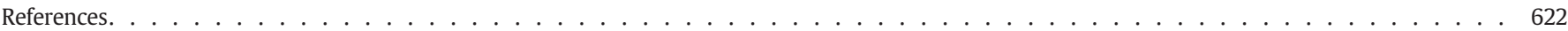

\section{Introduction}

\subsection{Systemic lupus erythematosus}

Systemic lupus erythematosus (SLE) is a systemic, autoimmune disorder that can involve multiple organ systems. It has a global prevalence of $20-150$ cases per 100,000 people [1,2], preferentially affecting women of childbearing age (female-to-male ratio is close to 9:1). Over the last four decades, there has been an increase in incidence as well as survival, reflecting the better diagnostic acuity, a better understanding of the pathogenesis of the disease and advances in the therapeutic approach [3]. The main cause of death is also changing. While in the past decade most patients died from infection and complications of active SLE, nowadays thrombotic events are becoming the most important cause of mortality [4-6].

\subsection{Neuropsychiatric SLE (NPSLE) - clinical features}

Central nervous system (CNS) involvement has been reported to occur in $12 \%$ to $95 \%$ of SLE patients [7]. This wide range in prevalence results from the multitude of manifestations recognized as neuropsychiatric (NP) systemic lupus erythematosus. In 1999, the American College of Rheumatology has defined 19 NPSLE syndromes [8], including 12 CNS and 7 peripheral nervous system manifestations (Table 1). Acquisition of valuable treatment strategies poses the need for early recognition of nervous system involvement in SLE and responses to the medication. However, there is also the issue of attribution of NP events to SLE as these conditions may arise from multiple causes, making it difficult to distinguish between NPSLE and other neurologic conditions [9]. More recently, in addition, SLE has been associated to an increased risk of dementia [10].

NPSLE remains a diagnostic challenge as there are no widely accepted biomarkers for patients who have subclinical involvement. Moreover, for patients with neuropsychiatric events, their lack of specificity for SLE makes attribution difficult despite advances in neuroimaging and other diagnostic strategies. It has been demonstrated that SLE patients have higher rates of post-steroid NP symptoms which might have erroneously been diagnosed as NPSLE, accounting for the wide range in prevalence [11]. Magnetic resonance imaging (MRI) is the imaging method of choice, where atrophy involving mainly the frontal and

\section{Table 1}

Neuropsychiatric syndromes in systemic lupus erythematosus as defined using the American College of Rheumatology nomenclature [8].

\begin{tabular}{ll}
\hline Central nervous system & Peripheral nervous system \\
\hline Aseptic meningitis & Guillain Barré syndrome \\
Cerebrovascular disease & Autonomic neuropathy \\
Demyelinating syndrome & Mononeuropathy \\
Headache & Myastenia gravis \\
Movement disorder & Cranial neuropathy \\
Myelopathy & Plexopathy \\
Seizure disorder & Polyneuropathy \\
Acute confusional state & \\
Anxiety disorder & \\
Cognitive disfunction & \\
Mood disorder & \\
Psychosis & \\
\hline
\end{tabular}

temporal grey matter and white matter is the hallmark of NPSLE [12]. Additionally, different NP syndromes and immunological patterns have been associated to specific imagiologic findings [13,14]. However, up to $50 \%$ of NPSLE patients have a normal exam [15]. On the other hand, non-NPSLE patients also have high rates of abnormal brain scans, indicating that MRI is not sufficient to diagnose CNS involvement [16]. Studies with functional MRI revealed an altered pattern of cortical activation in sensorimotor areas, as well as in some regions of the frontal and parietal lobes and in the visual pathway [17]. A study with ${ }^{18}$ fluorodeoxyglucose $\left({ }^{18} \mathrm{FDG}\right)$ PET imaging to measure blood flow and glucose uptake in the brains of newly diagnosed SLE patients without neurologic symptoms revealed increased ${ }^{18} \mathrm{FDG}$ uptake (hypermetabolism) in the white matter, which correlated with higher scores of disease activity index [18]. Taken together, these findings suggest that overall lupus inflammatory activity is associated with inflammation in the white matter of patients with SLE, irrespective of NP manifestations.

\subsection{Neuropsychiatric SLE (NPSLE) - pathophysiology}

NPSLE is a complex and incompletely understood medical condition. Its pathophysiology is multifactorial and involves auto-antibody mediated neuronal cell damage, immune complex depositions, inflammatory and/or thrombotic microangiopathy, damage to the blood-brain barrier and intrathecal production of proinflammatory cytokines [19,20]. An inflammatory state may begin early in the course of the disease, accompany disease relapses and eventually result in neuronal death [18].

More specifically, increased susceptibility to NPSLE has been described in patients with apolipoprotein E polymorphism [21] which is itself associated to an increased risk of Alzheimer's disease [22]. More recently, an increased risk of NPSLE has been described to occur in patients with TREX 1 gene variants, involved in the regulation of apoptosis and oxidative stress [23]. Anti-phospholipid antibodies are the autoantibodies with the highest potential to cause brain damage in LES patients. A significantly greater proportion of NPSLE patients have positive titers as compared to non-NPSLE [24]. The exact pathogenic mechanism of these antibodies is unknown but increasing evidence supports the idea that, besides having a direct prothrombotic effect, anti-phospholipid antibodies increase the expression of cell-adhesion molecules and proinflammatory cytokines in the endothelium, thereby increasing local inflammatory response $[25,26]$. Some studies also suggest that anti-phospholipid antibodies directly bind to the neural tissue, deregulating their functions and having an immediate pathogenic effect [27]. Anti-neuronal antibodies with direct cytotoxic effects also have an important role in the physiopathology of NPSLE [24]. Anti-ribosomal P were related to hippocampal atrophy and memory impairment in these patients [28] [29]. Elevated anti-ribossomal P, both in serum and cerebrospinal fluid, was also reported to have a strong association with lupus related psychosis [30,31]. Antibodies against NMDA receptor, which is responsible for activity-dependent synaptic plasticity and long-term potentiation that underlie memory and learning [32,33], are significantly augmented in the serum of NPSLE patients [34]. The presence of anti-microtubule-associated protein 2 antibodies also correlated with neuropsychiatric manifestations in SLE, namely psychosis, seizures, neuropathy, and cerebritis [35].Increased cerebrospinal fluid levels of several cytokines, namely interleukin-6, interleukin-8 [36], interleukin-1ß, interleukin-10 and tumor necrosis factor $\alpha$ (TNF $\alpha$ ) were demonstrated in several studies [37]. These proinflammatory cytokines promote the synthesis of proteolytic enzymes, metalloproteinases, 
which in turn induce damage to the brain parenchyma. Intrathecal levels of matrix metalloproteinase- 9 are elevated in SLE with CNS involvement and its levels correlate with those of interleukin 6 and 8 [25]. Corroborating this data, a significant increase in soluble biomarkers of neuronal and astrocytic cell death, such as neurofilament, Tau and astroglial fibrillary acidic protein in the cerebrospinal fluid of NPSLE patients has been demonstrated [38]. Recent research revealed the importance of type I interferon a signalling as cytokine abrogation was sufficient to prevent synapse loss and some behavioural phenotypes in lupus-prone mice [39]. In addition, mitochondrial dysfunction and disruption of neuron-glia metabolic coupling occurring as a result of the increased oxidative stress are observed in the brain of patients with systemic inflammation. This leads to decreased expression of genes associated with synaptic plasticity and increased expression of stress-response genes [40,41]. Additionally, reactive oxygen species, together with activated immune cells and proinflammatory cytokins, like TNF- $\alpha$ and interleukin- $1 \beta$, can directly induce neuronal apoptosis $[7,42]$. Taken together these findings indicate that systemic inflammation leads to an energy crisis of the brain that reduces its synaptic activity, thus resembling the hallmarks of the aged brain [7].

\subsection{Central nervous system degeneration in SLE}

The definition of neurodegeneration is neither simple nor consensual, although universally accepted. In the strict sense of the word, neurodegeneration corresponds to any pathological condition in which there is primary loss of structure and/or function of neurons. In practice, neurodegenerative diseases represent a large group of neurological disorders with heterogeneous clinical and pathological expressions affecting specific subsets of neurons in specific functional anatomic systems. Furthermore, they are characterized by having a chronic relentless course and an essentially unknown cause. Even when its cause is known, for example in the case of Huntington's disease (defective huntingtin caused by a mutation in HTT gene), the mechanism by which it initiates the disease remains speculative [43]. Currently the number of neurodegenerative syndromes reaches a few hundred, the vast majority of which exhibits diffuse or focal loss of neurons with reactive gliosis [43]. At least four main types of distinct neuronal death have been defined: apoptotic, necrotic, autophagic, and cytoplasmic [44]. A common misconcept is the belief that only necrosis elicits inflammation. The higher grade of inflammatory reaction in regions of necrosis may simply reflect the higher number of dead cells. In the brain microenvironment, especially in the context of neurodegeneration, the inflammatory response is mainly local, even for necrosis. In other words, the main cellular effectors are resident microglia and astrocytes, instead of blood-borne neutrophils and monocytes [45].

The immune and nervous systems have coevolved from early invertebrates to higher mammals, creating intricate cross-talk mechanisms. This is not surprising since glial cells constitute no less than half the cells in a mammalian brain [7]. Data from animal studies suggest that both acute high bursts of systemic inflammation [46] or transient low dose bouts can induce permanent brain dysfunction [47]. On the other hand, intracerebroventricular minocycline injection, a tetracycline derivative which reduces blood-brain barrier permeability and inhibits activation and proliferation of microglia, protects septic mice against longterm memory impairment [48]. Animal studies also demonstrate that systemic inflammation induces brain NADPH oxidative activity and nitric oxide synthase (iNOS), with a significant increase in oxidative stress. Moreover, experimental administration of the anti-oxidants $\mathrm{N}$ acetylcysteine and deferoxamine shortly after murine sepsis resulted in long-term neuroprotective effects [49].

\section{The eye in SLE}

SLE may affect almost any ocular structure, namely the eyelid, conjunctiva, episclera, sclera, cornea, retina, retinal vasculature, uveal tract, optic nerve and orbit (1). Up to one-third of patients present ocular manifestations, which may precede extra-ocular systemic disease [50]. Among these, posterior segment involvement may correlate with SLE activity and/or CNS lupus (Table 2) [50].

Next we shall describe in, more detail, manifestations in specific ocular compartments that may be associated to clinical or subclinical neuronal involvement.

\subsection{The optic nerve}

Neuro-ophthalmic manifestations are rare, optic neuropathy being the most common complication [52]. It most frequently manifests as optic neuritis, with a moderate to poor visual prognosis [51] and a favourable response to prompt steroid therapy [57,58]. Neuromyelitis optica in patients testing positive for aquaporin-4 autoantibody has also been described in SLE patients [59]. In this case the prognosis for functional recovery is worse, even with high-dose corticotherapy or plasmapheresis. Ischemic optic neuropathy $[60,61]$ or chiasmopathy [57] may also occur.

\subsection{The choroid}

Histopathology studies of the choroid have shown inflammatory cell infiltrates within the choroid, as well as immunoglobulin and complement deposition in the choroidal vasculature and damage to the retinal pigment epithelium [62]. There is a wide spectrum of manifestations. Lupus choroidopathy can occur isolated or associated with retinopathy. Subtle and subclinical changes in choroidal circulation have also been demonstrated with indocyanine angiography in SLE patients with nephropathy and no other signs of ophthalmic involvement [54]. On the other hand it can present with serous retinal detachment, retinal pigment epithelium detachment, retinal pigment epitheliopathy, choroidal ischemia or effusion [50]. Lupus choroidopathy is usually a marker of high disease activity, often correlated with CNS and renal disease [63].

\subsection{The retina}

Retinal involvement depends on the systemic control of disease activity [64] and is strongly correlated to CNS involvement [55]. Damage to the retina can be induced directly as a result of three main mechanisms: microangiopathy, retinal vasculitis and/or severe vaso-occlusion. Microangiopathy results from immune complexes deposition in vessel walls and microemboli, which translates in intraretinal haemorrhages, hard exudates, microaneurysms and cotton wool spots. Histopathology reveals immunoglobulin and complement deposits, perivascular monocellular infiltrate and rarely fibrinoid necrosis [63,65]. Retinal vasculitis, affecting both veins and arterioles, is a much rarer presentation with a significantly worse prognosis than microangiopathy. The finding of retinal vasculitis correlates with anti-phospholipid syndrome as well as with the presence of CNS vasculitis [56,66]. Histopathologic specimens show fibrinoid change with thrombus formation without a true arteritis [67]. Severe vaso-occlusion has a spectrum of clinical presentations ranging from occlusion of major retinal veins or arteries to microembolisation of multiple small vessels presenting as Purtscherlike retinopathy [50]. Indirect retinal damage can also occur secondary to systemic hypertension from renal involvement or prolonged corticosteroid therapy.

Besides the above-mentioned clinical findings, retinal involvement may be slowly progressive and subclinical. The retina is a neuronal tissue with the same embryologic origin as the brain. It also contains neurons - the ganglion cells - and unmyelinated axons - the retinal nerve fiber layer (RNFL) - making it an ideal tissue to study CNS alterations. In fact, early retinal changes that occur in neurodegenerative diseases such as multiple sclerosis [68], Alzheimer's disease [69] and Parkinson's disease [70] can be tracked with optical coherence tomography (OCT). These changes consist of macular thinning, mainly involving retinal 
Table 2

Posterior segment involvement in SLE.

\begin{tabular}{|c|c|c|c|}
\hline & Optic nerve & Choroid & Retina \\
\hline Prevalence & $1 \%$ & $<1 \%$ & $3 \%$ to $29 \%$ \\
\hline Presentation & $\begin{array}{l}\text { Optic neuritis, ischemic } \\
\text { optic neuropathy }\end{array}$ & $\begin{array}{l}\text { Serous retinal detachment, retinal pigment epithelium detachment, retinal } \\
\text { pigment epitheliopathy, choroidal ischemia, choroidal effusion }\end{array}$ & $\begin{array}{l}\text { Microangiopathy, retinal vasculitis } \\
\text { and severe vaso-occlusion }\end{array}$ \\
\hline Visual prognosis & Moderate to poor & $x^{2}$ & Depends on the type of presentation \\
\hline $\begin{array}{l}\text { Association to systemic } \\
\text { lupus erythematosus }\end{array}$ & Yes & Yes & Yes \\
\hline Association to CNS lupus & No & Yes & Yes \\
\hline \multirow[t]{2}{*}{ References } & Frigui et al. [51] & Nguyen et al. [53] & Stafford-Brady et al. [55] \\
\hline & Man et al. [52] & Baglio et al. [54] & Jabs et al. [56] \\
\hline
\end{tabular}

nerve fiber layer, ganglion cell layer and ganglion cell complex (GCC), comprising the ganglion cell layer and inner plexiform layer. Neuronal retinal loss can actually be detected even in patients without afferent visual defects.

The rational for retinal thinning in SLE involves both direct retinal damage and trans-synaptic retrograde degeneration (TRD). IgG immune complexes in the walls of retinal vessels are reportedly associated to RNFL microinfarcts and ganglion cell atrophy [71]. Anti-NMDA antibodies directed against NMDA receptors present on the surface of ganglion cells may also be pathogenic [72]. Moreover, TRD of neurons is a process occurring after central nervous system lesions, in which degeneration of the axon proceeds towards the cell body, as opposed to anterograde (Wallerian) degeneration. This results in a neurotoxic microenvironment that leads to secondary degeneration of adjacent neurons [73]. Optic disc pallor and band atrophy in individuals with congenital occipital lesions have been described [74] and TRD of retinal ganglion cells has been further described in acquired occipital lobe lesions [75-77]. Overall, both inflammation and neurodegeneration of the posterior visual pathway may be accompanied by early retinal changes.

\subsection{The retrochiasmal visual pathway}

Eye movement disorders are common in SLE. They have been reported in up to $29 \%$ patients, often as a result of brainstem infarction [78]. Visual cortex involvement can cause visual hallucinations, visual field defects, nystagmus, and cortical blindness [63]. Idiopathic intracranial hypertension has also been reported both in children and adults and may rarely be the presenting manifestation of SLE $[79,80]$.

\section{Imaging the retina, optic nerve and choroid in SLE}

\subsection{Fundus fluorescein angiography and indocyanine angiography}

Fundus fluorescein angiography (FFA) is an invasive method that may be helpful in identifying subclinical signs of retinopathy, manifesting as leakage, retinal capillary dilatation and microaneurysms in patients with mild-to-moderate disease activity. It can also reveal optic disc edema in cases of optic neuropathy. In severe vaso-occlusive retinopathy, FFA may present major artery or vein occlusions or multiple microembolisation in small vessels presenting as Purtscher-like retinopathy $[81,82]$. The choroid can also be evaluated with FFA, which may present delayed choroidal filling or areas of choroidal nonperfusion. In more severe choroidopathy, FFA may reveal multifocal areas of subretinal leakage with pooling, corresponding to the areas of exudative retinal detachment [53]. However, indocyanine green angiography (IGA) is a more valuable exam to evaluate choroidal pathology. Typically, it presents with focal, transient early-phase hypofluorescence secondary to perfusion delay followed by late-phase diffuse hyperfluorescence due to vascular hyperpermeability. More subtle findings include distortion of the large choroidal vessels and also pinpoint clusters of choroidal hyperfluorescence in the intermediate phase that may represent immune deposition in deeper layers of choroidal stroma or Bruch membrane [83].

\subsection{Spectral domain optical coherence tomography}

Spectral domain optical coherence tomography (SD-OCT) is a reliable, non-invasive, trans-pupillary technique that provides highresolution cross-sectional images of the retina and the optic nerve head, using a principle analogous to B-scan ultrasound. A beam of infrared light strikes the retina and the delayed light reflected from the various layers of the retina and choroid is compared to a reference beam projected against a mirror. The elaboration of the three-dimensional image is made based on the principles of low-coherence interferometry. This method provides detailed data on the morphology and reproducibly measures the thickness and volume of optic nerve, peripapillary area and the various retinal layers at the macular level (Figs. 1 and 2).

Classical OCT devices like time-domain OCT were unhelpful in choroidal imaging, as the retinal pigment epithelium blocked the signal from the choroid. New software for SD-OCT - enhanced depth imaging (EDI) - maximizes sensitivity and detail by moving the peak of the sensitivity curve to the sclera (Fig. 3). Thus it provides a better view of the choroidal cross-sectional structure, thickness and choroidal-scleral interface [84]. However, the few studies on choroidal thickness in SLE patients revealed contradictory results. According to Altinkaynak et al. SLE patients had thinner choroids than age and gender-matched controls [85]. On the other hand, Ferreira et al. reported thicker choroids in these patients [86]. This difference may be due to the systemic disease activity state as in the first study all patients were "inactive" whereas in the latter study the disease activity state was not accessed. An increase in choroidal thickness with systemic inflammatory activity has also been described in Behçet disease [87,88].

More recently, a new OCT system - optical coherence tomography angiography (OCTA) - has the ability to show both structural and blood flow information without requiring intravenous contrast. This innovative technology, called split-spectrum amplitude decorrelation angiography, is based on the comparison of multiple B scans acquired consecutively in the same spot. In the case of stationary tissues or cells, there is a high correlation between consecutive images. For moving cells, such as blood cells inside the vessels, there is a low correlation (or high decorrelation) between consecutive images, thereby revealing the microvascular architecture [89].

Studies regarding retinal thickness measurements have yielded contradictory results (Table 3 ) likely explained on the basis of small sample size and heterogeneity of clinical NPSLE manifestations and SLE systemic disease activity [90,91].

Longitudinal studies as well as studies with larger samples are needed to evaluate the real potential of OCT to detect early neurodegenerative changes and to eliminate the effect of potential confounders 

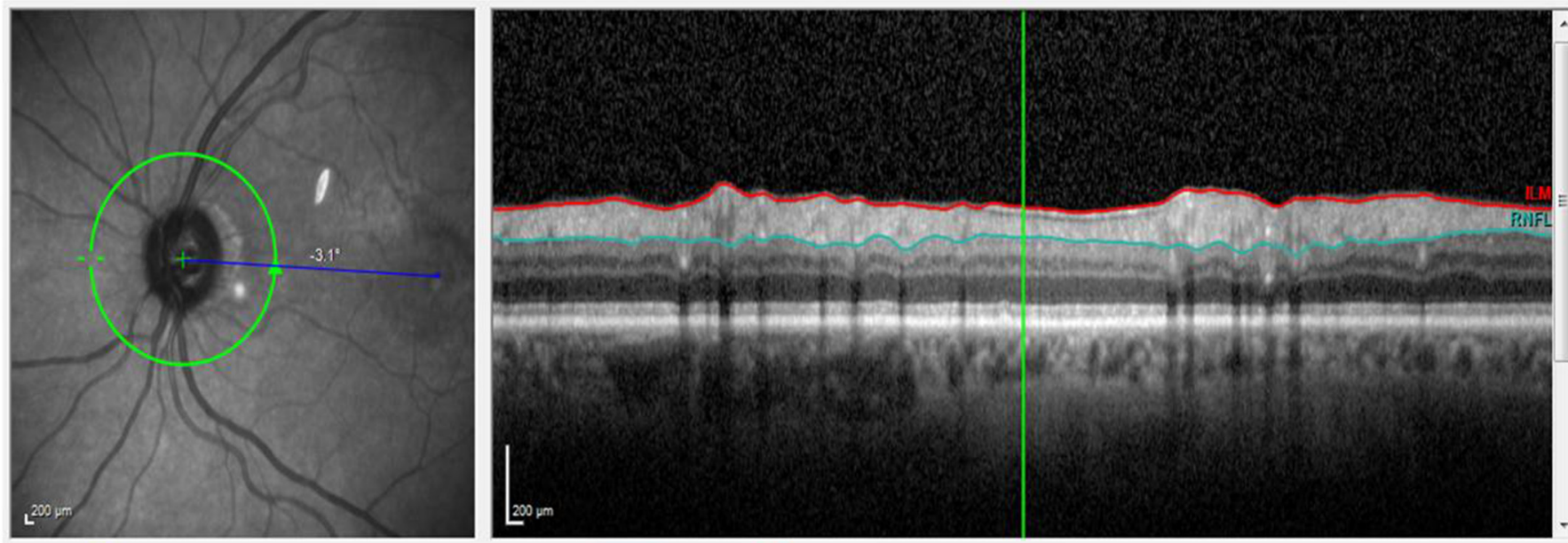

(3)

Peripapillary RNFLT Classification

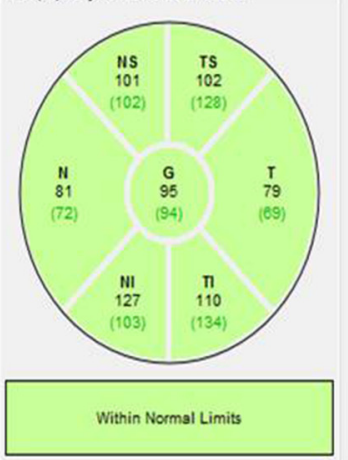

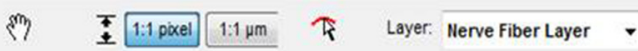

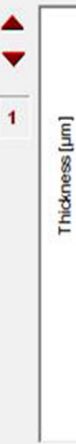

Reference database: European Descent (2009)

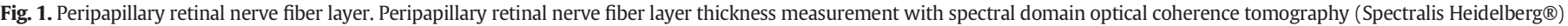
and comparison to a sex and age-matched database. ILM - internal limiting membrane; RNFL - retinal nerve fiber layer.

such as the effect of ocular axial length, intraocular pressure, ophthalmic pathologies, systemic medications like hydroxychloroquine and other systemic comorbidities, like diabetes mellitus, that potentially affect retinal thickness [92]. Standardised questionnaires may also offer valuable help for screening practices.

\section{Conclusion}

The retina is an extension of the central nervous system; retinal ganglion cells and their axons forming the optic nerve are similar to CNS neurons and the retinal and cerebral vasculature share anatomic,

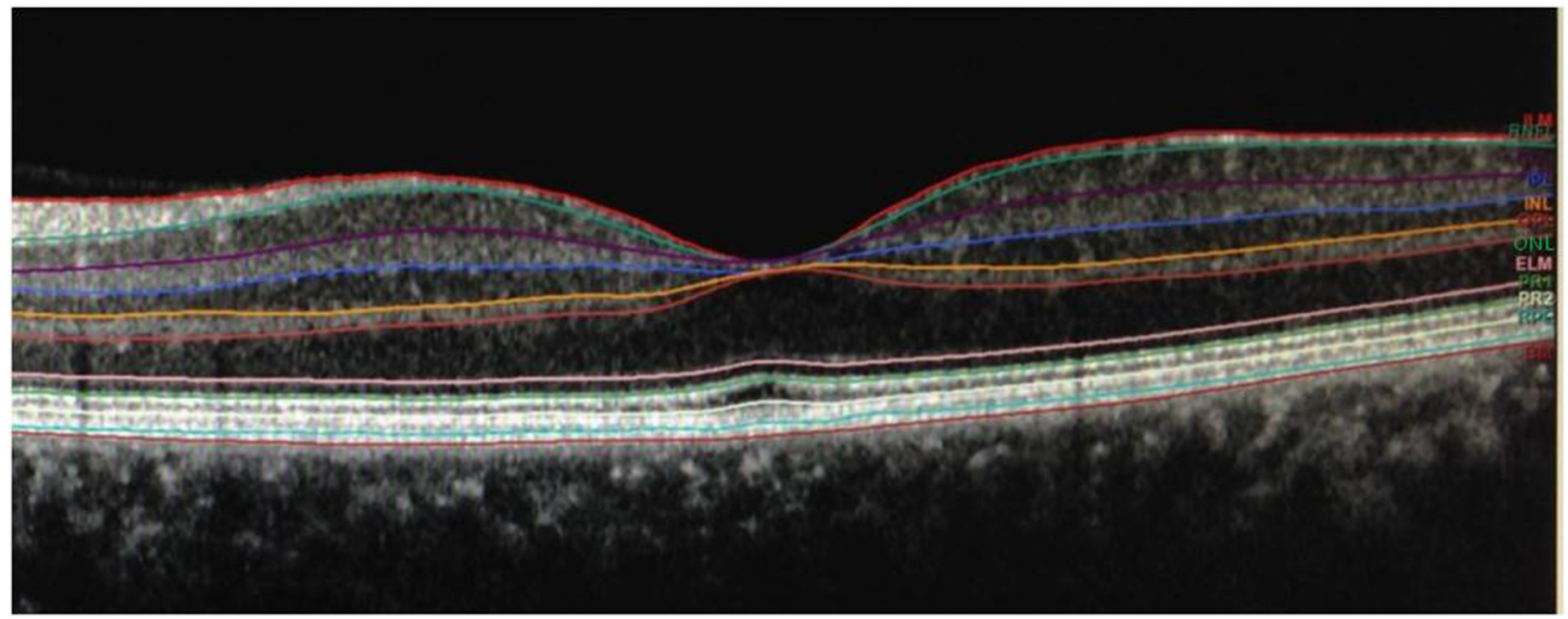

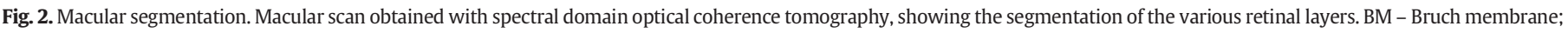

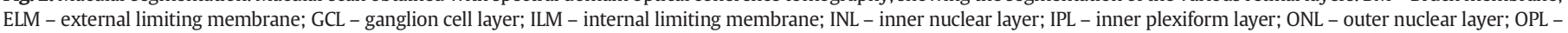
outer plexiform layer; PR1 - photoreceptors inner segments; PR2 - photoreceptors outer segments; RPE - retinal pigment epithelium. 

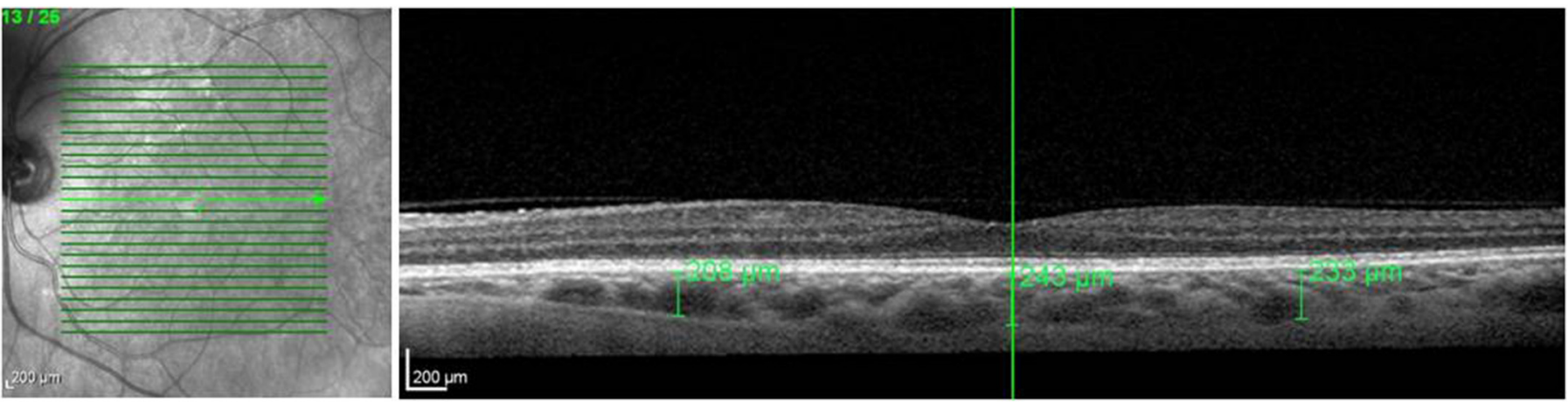

Fig. 3. Choroid. Choroidal thickness, measured using enhanced depth imaging (EDI) software for spectral domain optical coherence tomography (Spectralis Heidelberg®).

Table 3

Published studies comparing retinal thickness and volume between NPSLE, non-NPSLE and healthy controls.

\begin{tabular}{|c|c|c|c|c|c|c|c|}
\hline & $\mathrm{N}$ & $\begin{array}{l}\text { Peripapillary retinal nerve } \\
\text { fiber layer }\end{array}$ & $\begin{array}{l}\text { Central } \\
\text { macular } \\
\text { thickness }\end{array}$ & $\begin{array}{l}\text { Central } \\
\text { macular } \\
\text { volume }\end{array}$ & $\begin{array}{l}\text { Macular inner } \\
\text { retinal complex }\end{array}$ & $\begin{array}{l}\text { Macular ganglion } \\
\text { cell complex }\end{array}$ & $\begin{array}{l}\text { Macular inner } \\
\text { nuclear layer }\end{array}$ \\
\hline $\begin{array}{l}\text { Liu et al. NPSLE patients } \\
\text { versus non-NPSLE [90] }\end{array}$ & $\begin{array}{l}15 \text { NPSLE vs } 16 \\
\text { non-NPSLE }\end{array}$ & No difference & No difference & $\begin{array}{l}\text { No } \\
\text { difference }\end{array}$ & No difference & No difference & No difference \\
\hline $\begin{array}{l}\text { Liu et al. NPSLE patients } \\
\text { versus healthy controls [90] }\end{array}$ & $\begin{array}{l}15 \text { NPSLE vs } 16 \text { healthy } \\
\text { controls }\end{array}$ & $\begin{array}{l}\downarrow \text { thickness } \\
\text { Global, temporal superior } \\
\text { and nasal } \\
(\mathrm{p}<0.05)\end{array}$ & No difference & $\begin{array}{l}\downarrow \text { thickness } \\
(\mathrm{p}<0.05)\end{array}$ & $\begin{array}{l}\downarrow \text { thickness } \\
(p<0.05)\end{array}$ & $\begin{array}{l}\downarrow \text { thickness } \\
(\mathrm{p}<0.05)\end{array}$ & No difference \\
\hline $\begin{array}{l}\text { Liu et al. } \\
\text { SLE versus healthy controls } \\
{[90]}\end{array}$ & $\begin{array}{l}31 \text { SLE vs } 16 \text { healthy } \\
\text { controls }\end{array}$ & $\begin{array}{l}\downarrow \text { thickness } \\
\text { Global, temporal superior } \\
\text { and nasal } \\
(\mathrm{p}<0.05)\end{array}$ & $\begin{array}{l}\downarrow \text { thickness } \\
(\mathrm{p}<0.05)\end{array}$ & $\begin{array}{l}\downarrow \text { thickness } \\
(\mathrm{p}<0.05)\end{array}$ & $\begin{array}{l}\downarrow \text { thickness } \\
(\mathrm{p}<0.05)\end{array}$ & $\begin{array}{l}\downarrow \text { thickness } \\
(\mathrm{p}<0.05)\end{array}$ & $\begin{array}{l}\downarrow \text { thickness } \\
(\mathrm{p}<0.05)\end{array}$ \\
\hline Shulman et al. [91] & $\begin{array}{l}14 \text { NPSLE, } 7 \text { non-NPSLE, } \\
11 \text { healthy controls }\end{array}$ & $\begin{array}{l}\text { No difference. } \\
\text { Trend towards lower } \\
\text { absolute values in NPSLE }\end{array}$ & N.A. & N.A. & N.A. & N.A. & N.A. \\
\hline
\end{tabular}

a Macular inner retinal complex: between the internal limiting membrane and the inner edge of the inner nuclear layer.

b Ganglion cell complex: between the outer edge of the RNFL and the inner edge of the inner nuclear layer.

physiological, and embryological similarities. Therefore, in some way the retina can be considered a "window to the brain". The utility of OCT in tracking early signs of neurodegeneration has been demonstrated in other pathologies. The idea of monitoring the neurodegenerative process associated with SLE would undoubtedly be an appealing one. It would enable a better control of CNS involvement since the early stages and open the way to studies in neuroprotection. However, so far, the studies conducted in SLE have given inconsistent results. Robust studies are further needed to access the real potential of ophthalmic imaging in studying neurodegenerative changes associated with SLE with respect to disease activity and cognition.

NPSLE is a frequent and severe complication of SLE, with a significant impact in quality of life and life expectancy. However, its diagnosis is an ongoing challenge given the multitude of clinical syndromes and the absence of reliable diagnostic tools. Imagiologic signs of brain inflammation or atrophy are a frequent finding, not only in NPSLE but also in SLE patients without neuropsychiatric manifestations. This suggests that neurodegeneration in LES is a relentless continuous process, starting long before the appearance of clinical signs of CNS involvement.

On the other hand, one can discuss the importance of this relentless neurodegenerative process in the algorithms of NPSLE: is it a pathophysiologic process behind several NP syndromes like movement disorders, anxiety, mood disorder, psychosis or cognitive disfunction? Or should we consider lupic neurodegeneration the 20th NP syndrome?

\section{Take-home messages}

- NPSLE is associated with a significant impact in morbidity and life expectancy.
- Early diagnosis of NPSLE is difficult as there are no widely accepted biomarkers.

- CNS inflammation and atrophy is present in lupus patients without NPSLE.

- Retinal thinning on SD-OCT is an established biomarker of neurodegeneration.

- Experimental models suggest that neuroprotection may be feasible and beneficial in systemic inflammation.

\section{Funding}

This research did not receive any specific grant from funding agencies in the public, commercial, or not-for-profit sectors.

\section{References}

[1] Pons-Estel GJ, Alarcón GS, Scofield L, Reinlib L, Cooper GS. Understanding the epidemiology and progression of systemic lupus erythematosus. Semin Arthritis Rheum 2010;39:257-68. https://doi.org/10.1016/j.semarthrit.2008.10.007.

[2] Danchenko N, Satia JA, Anthony MS. Epidemiology of systemic lupus erythematosus: a comparison of worldwide disease burden. Lupus 2006;15:308-18. https://doi.org/ 10.1191/0961203306lu2305xx.

[3] Alonso MD, Llorca J, Martinez-Vazquez F, Miranda-Filloy JA, Diaz de Teran T, Dierssen T, et al. Systemic lupus erythematosus in northwestern Spain: a 20-year epidemiologic study. Medicine (Baltimore) 2011;90:350-8. https://doi.org/10. 1097/MD.0b013e31822edf7f.

[4] Cervera R, Khamashta MA, Hughes GRV. The Euro-lupus project: epidemiology of systemic lupus erythematosus in Europe. Lupus 2009;18:869-74. https://doi.org/ $10.1177 / 0961203309106831$.

[5] Cervera R, Khamashta MA, Font J, Sebastiani GD, Gil A, Lavilla P, et al. Morbidity and mortality in systemic lupus erythematosus during a 10-year period a comparison of early and late manifestations in a cohort of. Mortality 2003;82:299-308. https://doi. org/10.1097/01.md.0000091181.93122.55. 
[6] Abu-Shakra M, Urowitz MB, Gladman DD, Gough J. Mortality studies in systemic lupus erythematosus. Results from a single center. II. Predictor variables for mortality. J Rheumatol 1995;22:1265-70.

[7] Sankowski R, Mader S, Valdés-Ferrer SI. Systemic inflammation and the brain: novel roles of genetic, molecular, and environmental cues as drivers of neurodegeneration. Front Cell Neurosci 2015;9:28. https://doi.org/10.3389/fncel.2015.00028.

[8] Liang MH, Corzillius M, Bae SC, Lew RA, Fortin PR, Gordon C, et al. The American College of Rheumatology nomenclature and case definitions for neuropsychiatric lupus syndromes. Arthritis Rheum 1999;42:599-608. https://doi.org/10.1002/1529-0131 (199904)42:4<599::AID-ANR2>3.0.CO;2-F.

[9] Preble JM, Silpa-archa S, Foster CS. Ocular involvement in systemic lupus erythematosus. Curr Opin Ophthalmol 2015;26:540-5. https://doi.org/10.1097/ICU. 0000000000000209.

[10] Goldacre MJ, Wotton CJ. Associations between specific autoimmune diseases and subsequent dementia: retrospective record-linkage cohort study, UK. J Epidemiol Community Health 2017;71:576-83. https://doi.org/10.1136/jech-2016-207809.

[11] Shimizu Y, Yasuda S, Kako Y, Nakagawa S, Kanda M, Hisada R, et al. Post-steroid neuropsychiatric manifestations are significantly more frequent in SLE compared with other systemic autoimmune diseases and predict better prognosis compared with de novo neuropsychiatric SLE. Autoimmun Rev 2016;15:786-94. https://doi.org/ 10.1016/j.autrev.2016.03.017.

[12] Sarbu N, Toledano P, Calvo A, Roura E, Sarbu MI, Espinosa G, et al. Advanced MR techniques: biomarkers in neuropsychiatric lupus. Lupus 2017;26:510-6. https:// doi.org/10.1177/0961203316674820.

13] Sarbu N, Alobeidi F, Toledano P, Espinosa G, Giles I, Rahman A, et al. Brain abnormalities in newly diagnosed neuropsychiatric lupus: systematic MRI approach and correlation with clinical and laboratory data in a large multicenter cohort. Autoimmun Rev 2015;14:153-9. https://doi.org/10.1016/j.autrev.2014.11.001

[14] Toledano P, Sarbu N, Espinosa G, Bargalló N, Cervera R. Neuropsychiatric systemic lupus erythematosus: magnetic resonance imaging findings and correlation with clinical and immunological features. Autoimmun Rev 2013;12:1166-70. https:// doi.org/10.1016/j.autrev.2013.07.004.

[15] Bertsias GK, Ioannidis JPA, Aringer M, Bollen E, Bombardieri S, Bruce IN, et al. EULAR recommendations for the management of systemic lupus erythematosus with neuropsychiatric manifestations: report of a task force of the EULAR standing committee for clinical affairs. Ann Rheum Dis 2010;69:2074-82. https://doi.org/10.1136/ard. 2010.130476.

[16] Sabbadini MG, Manfredi AA, Bozzolo E, Ferrario L, Rugarli C, Scorza R, et al. Central nervous system involvement in systemic lupus erythematosus patients without overt neuropsychiatric manifestations. Lupus 1999;8:11-9. https://doi.org/10. 1191/096120399678847344.

[17] Postal M, Lapa AT, Reis F, Rittner LAS. Magnetic resonance imaging in neuropsychiatric systemic lupus erythematosus: current state of the art and novel approaches. Lupus 2017;26:517-21.

[18] Ramage AE, Fox PT, Brey RL, Narayana S, Cykowski MD, Naqibuddin M, et al. Neuroimaging evidence of white matter inflammation in newly diagnosed systemic lupus erythematosus. Arthritis Rheum 2011;63:3048-57. https://doi.org/10.1002/art. 30458.

[19] Brey RL. Neuropsychiatric lupus: clinical and imaging aspects. Bull NYU Hosp Jt Dis 2007;65:194-9. https://doi.org/10.1016/j.rdc.2005.01.007.

[20] Stock AD, Gelb S, Pasternak O, Ben-Zvi A, Putterman C. The blood brain barrier and neuropsychiatric lupus: new perspectives in light of advances in understanding the neuroimmune interface. Autoimmun Rev 2017;16:612-9. https://doi.org/10 1016/j.autrev.2017.04.008.

[21] Pullmann Jr R, Skerenova M, Hybenova J, Lukac J, Rovensky J, Pullmann R. Apolipoprotein E polymorphism in patients with neuropsychiatric SLE. Clin Rheumatol 2004:23:97-101. https://doi.org/10.1007/s10067-003-0796-0.

[22] van der Weide J, Steijns LS, Teepen JL, Noback WJ, Klaverwijden G. Apolipoprotein E polymorphism and Alzheimer disease. Tijdschr Gerontol Geriatr 1996;27:73-7. https://doi.org/10.1001/archneur.57.6.824.

[23] de Vries B, Steup-Beekman GM, Haan J, Bollen EL, Luyendijk J, Frants RR, et al. TREX1 gene variant in neuropsychiatric systemic lupus erythematosus. Ann Rheum Dis 2010;69:1886-7. https://doi.org/10.1136/ard.2009.114157.

[24] Ho RC, Thiaghu C, Ong H, Lu Y, Ho CS, Tam WW, et al. A meta-analysis of serum and cerebrospinal fluid autoantibodies in neuropsychiatric systemic lupus erythematosus. Autoimmun Rev 2016;15:124-38. https://doi.org/10.1016/j.autrev.2015.10.003.

25] Trysberg E, Tarkowski A. Cerebral inflammation and degeneration in systemic lupus erythematosus. Curr Opin Rheumatol 2004;16:527-33. https://doi.org/10.1097/01. bor.0000135451.85671.14

[26] Negrini S, Pappalardo F, Murdaca G, Indiveri F, Puppo F. The antiphospholipid syndrome: from pathophysiology to treatment. Clin Exp Med 2016:1-11. https://doi. org/10.1007/s10238-016-0430-5.

[27] Rodrigues CEM, Carvalho JF, Shoenfeld Y. Neurological manifestations of antiphospholipid syndrome. Eur J Clin Invest 2010;40:350-9. https://doi.org/10. 1111/j.1365-2362.2010.02263.x.

[28] Appenzeller S, Carnevalle A, Li L, Costallat L, Cendes F. Hippocampal atrophy in systemic lupus erythematosus. Ann Rheum Dis 2006;65:1585-9. https://doi.org/10. 1136/ard.2005.049486.

[29] Bravo-Zehnder M, Toledo EM, Segovia-Miranda F, Serrano FG, Benito MJ, Metz C et al. Anti-ribosomal p protein autoantibodies from patients with neuropsychiatric lupus impair memory in mice. Arthritis Rheumatol 2015;67:204-14. https://doi. org/10.1002/art.38900.

[30] Hirohata S, Arinuma Y, Takayama M, Yoshio T. Association of cerebrospinal fluid anti-ribosomal p protein antibodies with diffuse psychiatric/neuropsychological syndromes in systemic lupus erythematosus. Arthritis Res Ther 2007;9:R44. https://doi.org/10.1186/ar2184.
[31] Briani C, Lucchetta M, Ghirardello A, Toffanin E, Zampieri S, Ruggero S, et al. Neurolupus is associated with anti-ribosomal P protein antibodies: an inception cohort study. J Autoimmun 2009;32:79-84. https://doi.org/10.1016/j.jaut.2008.12. 002.

[32] Lauvsnes MB, Omdal R. Systemic lupus erythematosus, the brain, and anti-NR2 antibodies. J Neurol 2012;259:622-9. https://doi.org/10.1007/s00415-011-6232-5.

[33] Lapteva L, Nowak M, Yarboro CH, Takada K, Roebuck-Spencer T, Weickert T, et al. Anti-N-methyl-D-aspartate receptor antibodies, cognitive dysfunction, and depression in systemic lupus erythematosus. Arthritis Rheum 2006;54:2505-14. https:// doi.org/10.1002/art.22031.

[34] Tay SH, Fairhurst AM, Mak A. Clinical utility of circulating anti-N-methyl-D-aspartate receptor subunits NR2A/B antibody for the diagnosis of neuropsychiatric syndromes in systemic lupus erythematosus and Sjögren's syndrome: an updated meta-analysis. Autoimmun Rev 2017;16:114-22. https://doi.org/10.1016/j.autrev.2016.12.002.

[35] Williams RC, Sugiura K, Tan EM. Antibodies to microtubule-associated protein 2 in patients with neuropsychiatric systemic lupus erythematosus. Arthritis Rheum 2004;50:1239-47. https://doi.org/10.1002/art.20156.

[36] Trysberg E, Carlsten H. Tarkowski a. Intrathecal cytokines in systemic lupus erythematosus with central nervous system involvement. Lupus 2000;9:498-503. https:// doi.org/10.1177/096120330000900704.

[37] Dellalibera-Joviliano R, Dos Reis ML, Queiroz Cunha F, De Donadi EA. Kinins and cytokines in plasma and cerebrospinal fluid of patients with neuropsychiatric lupus. J Rheumatol 2003;30:485-92 [doi:0315162X-30-485 [pii].

[38] Trysberg E, Nylen K, Rosengren LE, Tarkowski A. Neuronal and astrocytic damage in systemic lupus erythematosus patients with central nervous system involvement. Arthritis Rheum 2003:48:2881-7.

[39] Bialas AR, Presumey J, Das A, van der Poel CE, Lapchak PH, Mesin L, et al. Microgliadependent synapse loss in type I interferon-mediated lupus. Nature 2017. https:// doi.org/10.1038/nature22821.

[40] Lu T, Pan Y, Kao S-Y, Li C, Kohane I, Chan J, et al. Gene regulation and DNA damage in the ageing human brain. Nature 2004;429:883-91. https://doi.org/10.1038/ nature02661.

[41] Lin MT, Beal MF. Mitochondrial dysfunction and oxidative stress in neurodegenerative diseases. Nature 2006;443:787-95. https://doi.org/10.1038/nature05292.

[42] Kaur C, Sivakumar V, Zou Z, Ling EA. Microglia-derived proinflammatory cytokines tumor necrosis factor-alpha and interleukin-1beta induce Purkinje neuronal apoptosis via their receptors in hypoxic neonatal rat brain. Brain Struct Funct 2014;219: 151-70. https://doi.org/10.1007/s00429-012-0491-5.

[43] Przedborski S, Vila M, Jackson-Lewis V. Neurodegeneration: what is it and where are we? J Clin Invest 2003;111:3-10. https://doi.org/10.1172/JCI200317522.

[44] Clarke PGH. Developmental cell death: morphological diversity and multiple mechanisms. Anat Embryol (Berl) 1990;181:195-213. https://doi.org/10.1007/ BF00174615.

[45] Clarke PGH. Apoptosis versus necrosis. Cell death. Dis Nerv Syst 1999:3-28. https:// doi.org/10.1007/978-1-4612-1602-5_1.

[46] d'Avila J da CP, Santiago APSA, Amâncio RT, Galina A, Oliveira MF, Bozza FA. Sepsis induces brain mitochondrial dysfunction. Crit Care Med 2008;36:1925-32. https:// doi.org/10.1097/CCM.0b013e3181760c4b.

[47] Anderson ST, Commins S, Moynagh PN, Coogan AN. Lipopolysaccharide-induced sepsis induces long-lasting affective changes in the mouse. Brain Behav Immun 2015;43:98-109. https://doi.org/10.1016/j.bbi.2014.07.007.

[48] Michels M, Vieira AS, Vuolo F, Zapelini HG, Mendonça B, Mina F, et al. The role of microglia activation in the development of sepsisinduced long-term cognitive impairment. Brain Behav Immun 2015;43:54-9.

[49] Barichello T, Machado RA, Constantino L, Valvassori SS, Réus GZ, Martins MR, et al. Antioxidant treatment prevented late memory impairment in an animal model of sepsis*. Crit Care Med 2007;35:2186-90. https://doi.org/10.1097/01.CCM. 0000281452.60683 .96 .

[50] Silpa-Archa S, Lee JJ, Foster CS. Ocular manifestations in systemic lupus erythematosus. Br J Ophthalmol 2016;100:135-41. https://doi.org/10.1136/bjophthalmol2015-306629.

[51] Frigui M, Frikha F, Sellemi D, Chouayakh F, Feki J, Bahloul Z. Optic neuropathy as a presenting feature of systemic lupus erythematosus: two case reports and literature review. Lupus 2011;20:1214-8. https://doi.org/10.1177/0961203311403344.

[52] Man BL, Mok CC, Fu YP. Neuro-ophthalmologic manifestations of systemic lupus erythematosus: a systematic review. Int J Rheum Dis 2014;17:494-501. https://doi. org/10.1111/1756-185X.12337.

[53] Nguyen QD, Uy HS, Akpek EK, Harper SL, Zacks DN, Foster CS. Choroidopathy of systemic lupus erythematosus. Lupus 2000;9:288-98. https://doi.org/10.1191/ 096120300680199024.

[54] Baglio V, Gharbiya M, Balacco-Gabrieli C, Mascaro T, Gangemi C, di Franco M, et al. Choroidopathy in patients with systemic lupus erythematosus with or without nephropathy. J Nephrol 2011;24:522-9. https://doi.org/10.5301/JN.2011.6244.

[55] Stafford-Brady FJ, Urowitz MB, Gladman DD, Easterbrook M. Lupus retinopathy. Patterns, associations, and prognosis. Arthritis Rheum 1988;31:1105-10.

[56] Jabs DA, Fine SL, Hochberg MC, Newman SA, Heiner GG, Stevens MB. Severe retinal vaso-occlusive disease in systemic lupus erythematous. Arch Ophthalmol 1986;104: 558-63. https://doi.org/10.1001/archopht.1986.01050160114025.

[57] Siatkowski RM, Scott IU, Verm AM, Warn AA, Farris BK, Strominger MB, et al. Optic neuropathy and chiasmopathy in the diagnosis of systemic lupus erythematosus. J Neuroophthalmol 2001;21:193-8.

[58] Lin Y-C, Wang A-G, Yen M-Y. Systemic lupus erythematosus-associated optic neuritis: clinical experience and literature review. Acta Ophthalmol 2009;87:204-10. https://doi.org/10.1111/j.1755-3768.2008.01193.x.

[59] Závada J, Nytrová P, Wandinger KP, Jarius S, Svobodová R, Probst C, et al. Seroprevalence and specificity of NMO-IgG (anti-aquaporin 4 antibodies) in patients with 
neuropsychiatric systemic lupus erythematosus. Rheumatol Int 2013;33:259-63. https://doi.org/10.1007/s00296-011-2176-4.

[60] Cordeiro MF, Lloyd ME, Spalton DJ, et al. Ischaemic optic neuropathy, transverse myelitis, and epilepsy in an anti-phospholipid positive patient with systemic lupus erythematosus. J Neurol Neurosurg Psychiatry 1994;57:1142-3.

[61] Massin M, Berche C, Ullern M, et al. Acute anterior ischemic optic neuropathy disclosing disseminated lupus erythematosus. Ophtalmologie 1987;1:61-3.

[62] Hannouche D, Korobelnik JF, Cochereau I, Hayem G, Beaudreuil J, Meyer O, et al. Systemic lupus erythematosus with choroidopathy and serous retinal detachment. Int Ophthalmol 1995;19:125-7. https://doi.org/10.1007/BF00133184.

[63] Palejwala NV, Walia HS, Yeh S. Ocular manifestations of systemic lupus erythematosus: a review of the literature. Autoimmune Dis 2012:1. https://doi.org/10.1155/ 2012/290898.

[64] Davies JB, Rao PK. Ocular manifestations of systemic lupus erythematosus. Curr Opin Ophthalmol 2008;19:512-8. https://doi.org/10.1097/ICU.0b013e3283126d34.

[65] Aronson AJ, Ordoñez NG, Diddie KR, Ernest JT. Immune-complex deposition in the eye in systemic lupus erythematosus. 1979;139. https://doi.org/10.1001/archinte. 1979.03630480084026.

[66] Montehermoso A, Cervera R, Font J, Ramos-Casals M, Garcia-Carrasco M, Formiga F, et al. Association of antiphospholipid antibodies with retinal vascular disease in systemic lupus erythematosus. Semin Arthritis Rheum 1999;28:326-32. https://doi. org/10.1016/S0049-0172(99)80017-1.

[67] Au A, O'Day J. Review of severe vaso-occlusive retinopathy in systemic lupus erythematosus and the antiphospholipid syndrome: associations, visual outcomes, complications and treatment. Clin Experiment Ophthalmol 2004;32:87-100. https://doi. org/10.1046/j.1442-9071.2004.00766.x.

[68] Gordon-Lipkin E, Chodkowski B, Reich DS, Smith SA, Pulicken M, Balcer LJ, et al. Retinal nerve fiber layer is associated with brain atrophy in multiple sclerosis. Neurology 2007;69:1603-9. https://doi.org/10.1212/01.wnl.0000295995.46586.ae.

[69] Cunha JP, Proença R, Dias-Santos A, Almeida R, Águas H, Alves M, et al. OCT in Alzheimer's disease: thinning of the RNFL and superior hemiretina. Graefes Arch Clin Exp Ophthalmol 2017. https://doi.org/10.1007/s00417-017-3715-9.

[70] Moschos MM, Chatziralli IP. Evaluation of choroidal and retinal thickness changes in Parkinson's disease using spectral domain optical coherence tomography. Semin Ophthalmol 2017:1-4. https://doi.org/10.1080/08820538.2017.1307423.

[71] Karpik AG, Schwartz MM, Dickey LE, Streeten BW, Roberts JL. Ocular immune reactants in patients dying with systemic lupus erythematosus. Clin Immunol Immunopathol 1985;35:295-312. https://doi.org/10.1016/0090-1229(85)90091-1.

[72] Diamond B. Antibodies and the brain: lessons from lupus. J Immunol 2010;185: 2637-40. https://doi.org/10.4049/jimmunol.1090080.

[73] Vanburen JM. Trans-synaptic retrograde degeneration in the visual system of primates. J Neurol Neurosurg Psychiatry 1963;26:402-9.

[74] Fletcher WA, Hoyt WF, Narahara MH. Congenital quadrantanopia with occipital lobe ganglioglioma. Neurology 1988;38:1892-4.

[75] Jindahra P, Petrie A, Plant GT. The time course of retrograde trans-synaptic degeneration following occipital lobe damage in humans. Brain 2012;135:534-41. https:// doi.org/10.1093/brain/awr324.

[76] Goto K, Miki A, Yamashita T, Araki S, Takizawa G, Nakagawa M, et al. Sectoral analysis of the retinal nerve fiber layer thinning and its association with visual field loss in homonymous hemianopia caused by post-geniculate lesions using spectral-domain optical coherence tomography. Graefes Arch Clin Exp Ophthalmol 2016;254: 745-56. https://doi.org/10.1007/s00417-015-3181-1.
[77] Anjos R, Vieira L, Costa L, Vicente A, Santos A, Alves N, et al. Macular ganglion cell layer and peripapillary retinal nerve fibre layer thickness in patients with unilateral posterior cerebral artery ischaemic lesion: an optical coherence tomography study. Neuro-Ophthalmol 2016;40. https://doi.org/10.3109/01658107.2015.1122814.

[78] Keane JR. Eye movement abnormalities in systemic lupus erythematosus. Arch Neurol 1995;52:1145-9.

[79] DelGiudice GC, Scher CA, Athreya BH, Diamond GR. Pseudotumor cerebri and childhood systemic lupus erythematosus. J Rheumatol 1986;13:748-52.

[80] Kuyucu S, Argin A, Kuyucu N, Ozen S. Systemic lupus erythematosus presenting with pseudotumor cerebri: a rare association. Turk J Pediatr 2007;49:98-101.

[81] Kunavisarut P, Pathanapitoon K, Rothova A. Purtscher-like retinopathy associated with systemic lupus erythematosus. Ocul Immunol Inflamm 2016;24:60-8. https://doi.org/10.3109/09273948.2014.932816.

[82] Wu C, Dai R, Dong F, Wang Q. Purtscher-like retinopathy in systemic lupus erythematosus. Am J Ophthalmol 2014;158:1335-1341.e1. https://doi.org/10.1016/j.ajo. 2014.09.001.

[83] Gharbiya M, Pecci G, Baglio V, Gargiulo A, Allievi F, Balacco-Gabrieli C. Indocyanine green angiographic findings for patients with systemic lupus erythematosus nephropathy. Retina 2006;26:159-64.

[84] Spaide RF, Koizumi H, Pozonni MC. Enhanced depth imaging spectral-domain optical coherence tomography. Am J Ophthalmol 2008;146:496-500. https://doi.org/ 10.1016/j.ajo.2008.05.032.

[85] Altinkaynak H, Duru N, Uysal BS, Erten Ş, Kürkcüoğlu PZ, Yüksel N, et al. Choroida thickness in patients with systemic lupus erythematosus analyzed by spectral-domain optical coherence tomography. Ocul Immunol Inflamm 2015:1-7. https:// doi.org/10.3109/09273948.2015.1006790.

[86] Ferreira CS, Beato J, Falcão MS, Brandão E, Falcão-Reis FCÂ. Choroidal thickness in multisystemic autoimmune diseases without ophthalmologic manifestations. Retina 2017:37:529-35.

[87] Kim M, Kim H, Kwon HJ, Kim SS, Koh HJ, Lee SC. Choroidal thickness in Behcet's uveitis: an enhanced depth imaging-optical coherence tomography and its association with angiographic changes. Invest Ophthalmol Vis Sci 2013;54(9):6033. https:// doi.org/10.1167/iovs.13-12231.

[88] Yesilirmak N, Lee W-H, Gur Gungor S, Yaman Pinarci E, Akkoyun I, Yilmaz G. Enhanced depth imaging optical coherence tomography in patients with different phases of Behcet's panuveitis. Can J Ophthalmol 2017;52:48-53. https://doi.org/10. 1016/j.jcjo.2016.07.020.

[89] Chalam K, Sambhav K. Optical coherence tomography angiography in retinal diseases. J Ophthalmic Vis Res 2016;11:84-92. https://doi.org/10.4103/2008-322X. 180709.

[90] Liu GY, Utset TO, Bernard JT. Retinal nerve fiber layer and macular thinning in systemic lupus erythematosus: an optical coherence tomography study comparing SLE and neuropsychiatric SLE. Lupus 2015;24:1169-76. https://doi.org/10.1177/ 0961203315582285.

[91] Shulman S, Shorer R, Wollman J, Dotan G, Paran D. Retinal nerve fiber layer thickness and neuropsychiatric manifestations in systemic lupus erythematosus. Lupus 2017:961203317703496. https://doi.org/10.1177/0961203317703496.

[92] Tavares Ferreira J, Alves M, Dias-Santos A, Costa L, Santos BO, Cunha JP, et al. Retinal neurodegeneration in diabetic patients without diabetic retinopathy. Invest Ophthalmol Vis Sci 2016;57. https://doi.org/10.1167/iovs.16-20215. 